\title{
Simulation of Conceptual Designs of a Three-Surface Stealth Strike Fighter
}

\author{
Yue Kuizhi* \\ Department of Airborne Vehicle Engineering, Naval Aeronautical and Astronautical University, Yantai, 264001, China \\ School of Aeronautic Science and Engineering, Beijing University of Aeronautics and Astronautics, Beijing 100191, China
}

\section{Chen ShiChun**}

School of Aeronautic Science and Engineering, Beijing University of Aeronautics and Astronautics, Beijing 100191, China

\section{Liu Wenlin* and Yu Dazhao*}

Department of Airborne Vehicle Engineering, Naval Aeronautical and Astronautical University, Yantai, 264001, China

\begin{abstract}
A conceptual design of a three-surface strike fighter was studied and stealth performance was taken into account to enhance survivability and battle effectiveness. CATIA was used to design the aircraft's three-dimensional prototype model and the weapon carriage arrangement was also studied. The aircraft's RCS characteristics and distributions under X, S, C, and L bands were simulated using the RCSPlus software, which is based on the PO method. Pressure and velocity distributions of the flow field were also simulated using CFD. A turbulence model was based on standard $k$ - $\varepsilon$ function and N-S functions were used during the CFD computation. Lift coefficients, drag coefficients, and lift-to-drag ratio were obtained by aerodynamic simulation. The results showed that: (1) the average value of head-on RCS between $\pm 30^{\circ}$ is below $-3.197 \mathrm{dBsm}$, and (2) the lift coefficient is 0.34674 , the drag coefficient is 0.04275 , and the lift-to-drag ratio is 8.11087 when the attack angle is $2.5^{\circ}$.
\end{abstract}

Key words: conceptual design, aircraft, three surfaces, stealth, CFD

\section{Introduction}

A "three-surface" aircraft consists of the canard, wing, and tail. Typical three-surface aircraft manufactured by the East and the West, like the Su-33, Su-37, and F-15S/MTD, indicate one developing trend of military aviation. The $5^{\text {th }}$ generation aircraft, or a stealth aircraft that has features of low observability, is also the main focus of the major powers. Many types of stealth aircraft are already in service or are being developed, such as the famous US F-22 Raptor [1], F-35 Light II [2], X-45 [3], and X-47[4]. The Fighter plane T-50, developed by Russia, share some features with the F-22 as a stealth aircraft. How to combine these features - a threesurfaces configuration and stealth technology - together, is becoming a hot topic among military forces and aircraft companies.

Three-surfaces and stealth aircraft have been explored in depth; [5] gives the results of water tunnel experiments on the research of a three-surfaces aircraft's flow separation and flow mechanism at a high angle of strike fight, [6] analyzes the flight wing load of a three-surfaces aircraft in maneuvering, and studies the optimization method of wing load distribution fitting three-surfaces aircraft; [7] studies the trim conditions of three- surfaces-canard tiltwing aircraft, from the angles of both flight performance and controlling efficiency, [8] studies the relationship between a three-surfaces aircraft's RCS and its vertical tail anhedral angle, and simulates its RCS from head, tail, and
This is an Open Access article distributed under the terms of the Creative Commons Attribution Non-Commercial License (http://creativecommons.org/licenses/by$\mathrm{nc} / 3.0 /$ ) which permits unrestricted non-commercial use, distribution, and reproduction in any medium, provided the original work is properly cited. (c) * PH.D, Corresponding author: yuekuizhi_2000@sohu.com
** PH.D, 
broadside aspects, [9] analyzes the RCS characteristics of military aircrafts with internal weapon bays or carrying external weapons, [10] describes the basic principles, methods, and key technologies of an aircraft's radar, infra-red, radio frequency, optical, and sound stealth technology, [11] simulates the fluent dynamic performance of aircraft equipped with a miniature rocket booster under the fuselage, using an unstructured grid, [12] introduces Boeing's experience on commercial aircraft designed with $\mathrm{CFD}$, and describes the procedure of conceptual design using CFD instead of approximate methods, wind tunnel experiments, and flight tests, [13] studies the application of an unstructured grid in the CFD-aviation field, [14] estimates the flight dynamics of a jet trainer and an unmanned fighter plane using CFD, and [15] studies the subsonic aerodynamics of a triangle wing whose leading edge's sweep angle is $65^{\circ}$, using a CFD method.

Generally, researchers have conducted relatively deep research on designing three-surfaces aircraft, stealth aircraft, and the conceptual designing of aircraft, using the CFD method. Nevertheless, there are still some problems in aircraft conceptual design; for example, there is no public research about stealth strike fighter design. Moreover, the integration analysis of stealth and aerodynamic conceptual design needs further work.

On the basis of the analysis above, this paper seeks to study the conceptual design, RCS characteristics, and aerodynamic performance of a three-surfaces stealth strike fighter, with an expectation of supplying some theoretical foundations and technical bases for military aircraft conceptual and stealth design.

\section{Theoretical Basis}

Radar wave scattering and aerodynamic characteristics analyses should be included in the conceptual design of stealth aircraft. The RCS computation algorithm and CFD turbulence models form the theoretical basis of aircraft conceptual design.

\subsection{RCS computation algorithm}

Scattering characteristics of a three-surfaces strike fighter were simulated using the private RCSPlus software, which uses physical optics (PO) methods for panel units and equivalent current methods for edge diffraction. The computation accuracy of this software has been verified by tests in microwave anechoic chambers.

The key expression of the PO method is: $\sqrt{\sigma_{p o}}=-\boldsymbol{j} \frac{k}{\sqrt{\pi}} \int_{s} \hat{\boldsymbol{n}} \cdot\left(\hat{\boldsymbol{e}}_{r} \times \widehat{\boldsymbol{h}}_{i}\right) \exp [\boldsymbol{j} \boldsymbol{k r}(\hat{\boldsymbol{i}}-\widehat{\boldsymbol{s}})] \mathrm{d} S$

The key expression of the equivalent current method is:

$$
\sqrt{\sigma_{\text {ecm }}}=\frac{1}{\sqrt{\pi} \sin \theta}\left[\left(\boldsymbol{E}_{o}^{i} \cdot \widehat{\boldsymbol{t}}\right) f \hat{\boldsymbol{s}} \times(\widehat{\boldsymbol{s}} \times \widehat{\boldsymbol{t}})-Z_{0}\left(\boldsymbol{H}_{0}^{i} \cdot \hat{\boldsymbol{t}}\right) g \widehat{\boldsymbol{s}} \times \hat{\boldsymbol{t}}\right] \cdot e^{-j 2 k \hat{\hat{r}} \cdot \hat{\boldsymbol{s}}} \frac{\sin (\hat{\boldsymbol{l}} \cdot \widehat{\boldsymbol{s}})}{k \hat{\boldsymbol{l}} \cdot \widehat{\boldsymbol{s}}}
$$

where $\sqrt{\sigma_{p o}}$ is the RCS of PO panel unit. $\sqrt{\sigma_{e c m}}$ is the RCS of equivalent current unit, both are defined in square meters. Other definitions can be found in [8][9].

The total RCS of a complex target like fighter plane can be expressed as

$$
\begin{aligned}
& \sigma=\left|\sum_{i=1}^{n}\left(\sqrt{\sigma_{p o}}\right)_{i}+\sum_{i=1}^{n}\left(\sqrt{\sigma_{e c m}}\right)_{i}\right|^{2} \\
& \bar{\sigma}=\frac{1}{N} \sum_{i=1}^{N} \sigma_{i} \\
& \sigma_{d B s m}=10 \lg _{10} \sigma
\end{aligned}
$$

where $\sigma$ is the RCS of a fighter plane, in square meters. $\bar{\sigma}$ is the RCS mean value of a fighter plane, in square meters. $\sigma_{d B s m}$ is the RCS in dBsm of a fighter plane.

\subsection{CFD turbulence models}

Standard $k-\varepsilon$ functions and three-dimensional N-S functions are used to simulate the turbulence models and fluent mechanic controlling of strike fight fighter respectively.

The standard $k-\varepsilon$ functions are:

$$
\begin{aligned}
& \frac{\partial(\rho k)}{\partial t}+\frac{\partial\left(\rho k u_{i}\right)}{\partial x_{i}}=\frac{\partial}{\partial x_{j}}\left[\left(\mu+\frac{\mu_{t}}{\sigma_{k}}\right) \frac{\partial k}{\partial x_{j}}\right]+G_{k}+G_{b}-\rho \varepsilon-Y_{M}+S_{k} \\
& \frac{\partial(\rho \varepsilon)}{\partial t}+\frac{\partial\left(\rho \varepsilon u_{i}\right)}{\partial x_{i}}=\frac{\partial}{\partial x_{j}}\left[\left(\mu+\frac{\mu_{t}}{\sigma_{\varepsilon}}\right) \frac{\partial \varepsilon}{\partial x_{j}}\right]+C_{1 \varepsilon} \frac{\varepsilon}{k}\left(G_{k}+C_{3 \varepsilon} G_{b}\right)-C_{2 \varepsilon} \rho \frac{\varepsilon^{2}}{k}+S_{\varepsilon}
\end{aligned}
$$

The fluent mechanic controlling N-S functions are:

$$
\begin{aligned}
& \frac{\partial \rho u}{\partial t}+\operatorname{div}(\rho u \vec{u})=\operatorname{div}(\mu \operatorname{grad} u)-\frac{\partial p}{\partial x}+S_{u} \\
& \frac{\partial \rho v}{\partial t}+\operatorname{div}(\rho v \vec{u})=\operatorname{div}(\mu \operatorname{grad} v)-\frac{\partial p}{\partial y}+S_{v} \\
& \frac{\partial \rho w}{\partial t}+\operatorname{div}(\rho w \vec{u})=\operatorname{div}(\mu \operatorname{grad} w)-\frac{\partial p}{\partial z}+S_{w}
\end{aligned}
$$

where $\rho$ is the fluid density, $k$ is turbulent kinetic energy, $\mathrm{t}$ is time, $u_{i}$ is time-average velocity, $\mu$ is coefficient of kinetic viscosity, $\mu_{t}$ is turbulent viscosity, $\sigma_{k}$ is the Prandtl number corresponding to $k$, and $G_{k}$ is the generation item of $k$ caused by the average velocity gradient. $G_{b}$ is the generation item of k caused by buoyancy, $\varepsilon$ is the dissipation rate of 
$k, Y_{M}$ represents the contribution of pulsation expansion to turbulence, $S_{k}$ is the source item defined by the user, $\sigma_{\varepsilon}$ is the Prandtl number corresponding to $\varepsilon, C_{1 \varepsilon}, C_{2 \varepsilon}$ and $C_{3 \varepsilon}$ are empirical constants, $S_{\varepsilon}$ is the source item defined by the user, $\vec{u}$ is the velocity vector, $u, v$, and $w$ is the projection of $\vec{u}$ onto the $x, y$, and $z$ axes, respectively. $p$ is the pressure on the fluid microelement, $\operatorname{div}()$ represents divergence, $\operatorname{grad}()$ represents gradient, $S_{u}, S_{v}, S_{w}$ are the generalized source items corresponding to $u, v$ and $w$ in the momentum conservation equation, respectively.

\section{Aircraft Conceptual Design}

The conceptual design of a three-surfaces strike fighter includes three-dimensional digital prototyping, weapon carriage arrangement, and basic parameters.
Three-dimensional digital prototyping is completed in CATIA, which features a single- seat, twin-engine, nose gear, and three-surfaces configuration. The movable surfaces include a pair of canards, a pair of leading edge flaps, a pair of flaperons, a pair of differential tailplanes, and a pair of all-moving vertical tails.

Stealth measures applied to this strike fighter includes: (1) edge-shaped front fuselage and smooth transition between cockpit and fuselage to ensure a relatively small RCS, (2) blended wing body configuration reduces fuselage RCS, (3) V-tail and outward slanted pelvic fins can reduce the broadside RCS, (4) divert-less supersonic inlet and S-shaped inlet can reduce the nose RCS, (5) parallel edges of wing and tails place their specular spikes into a common direction, (6) embedded weapon bay reduces the RCS, (7) edges of hatch doors, such as the doors of the weapon bay and the landing gear compartment, are saw tooth-shaped,

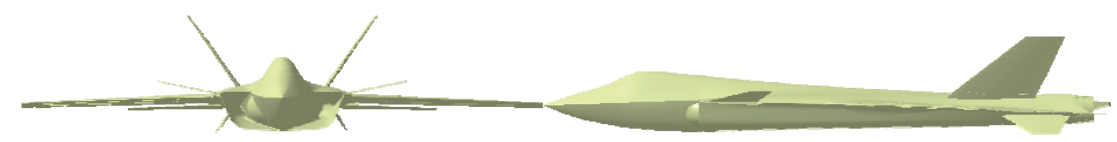

(a) front view

(b) side view

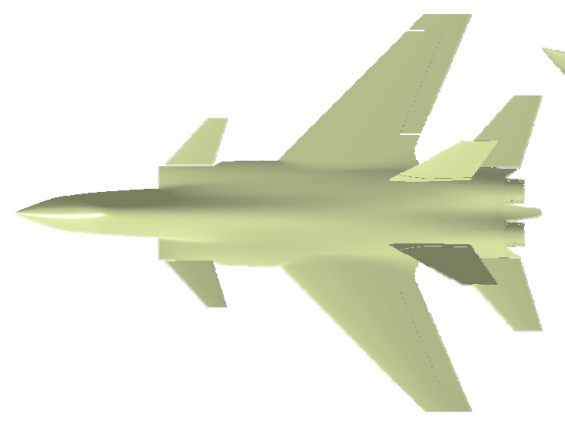

(c) top view

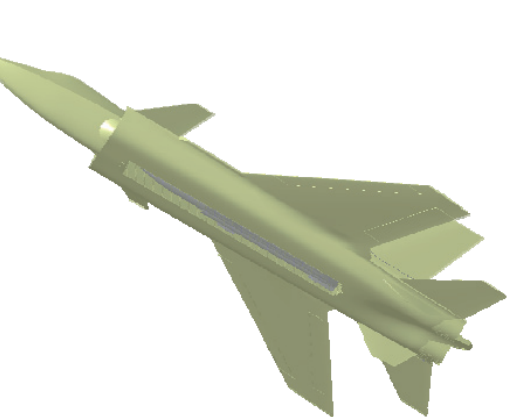

(d) 3D image

Fig. 1. 3D digital prototyping of a strike fighter

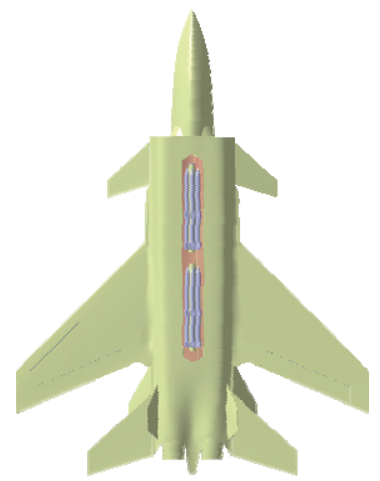

(a) Carriage arrangement I

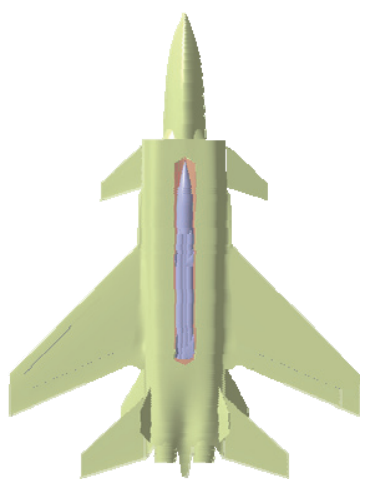

(b) Carriage arrangement II

Fig. 2. Fighter's weapon carriage arrangements 
to reduce the perpendicular RCS. Fig. 1 illustrates all these stealth measures incorporated in the digital prototyping.

Weapon carriage arrangements include: (1) 10 air-to-air missiles carried in the embedded weapon bay to execute stealth air combat missions, (2) one long-range air-to-ship missile carried in the embedded weapon bay to execute a stealth anti-ship mission. Fig. 2 illustrates the weapon carriage arrangements.

Table 1 gives the basic parameters of digital prototyping of the three-surfaces aircraft in conceptual design.

Stealth performance and aerodynamic characteristics of the digital prototyping should be analyzed after conceptual design, to estimate the advantages and disadvantages of the project.

Table 1. Basic parameters of the strike fighter

\begin{tabular}{cc}
\hline Type & Parameter \\
\hline Length & $21.949 \mathrm{~m}$ \\
Height & $5.82 \mathrm{~m}$ \\
Wing span & $16.742 \mathrm{~m}$ \\
Sweep angle of leading edge & $45^{\circ}$ \\
Sweep angle of trailing edge & $23^{\circ}$ \\
Chord length of wingtip & $1.915 \mathrm{~m}$ \\
Chord length of wing-body & $6.718 \mathrm{~m}$ \\
Engines number & 2 \\
Canard airfoil & NACA64a202 \\
Wing airfoil & NACA64a204 \\
Horizontal tail airfoil & NACA64a202 \\
Vertical tail airfoil & NACA64a003 \\
\hline
\end{tabular}

\section{Simulation}

Simulation work in aircraft conceptual design consists of RCS computation and aerodynamic simulations.

\subsection{RCS computation}

The digital prototyping of strike fighter designed in the conceptual design phase is used to finish the RCS computation work. The private RCS software 'RCSPlus' was used. This software is programmed on the basis of PO, as introduced in formulae 1-5. The correctness of this software has been validated by many RCS measurements in our microwave anechoic chamber. Section 3.1 presents a parametric study on aircraft's RCS and relevant contents can also be found in [8] and [9]. RCS simulation results: (1) Fig. 3 shows the RCS distribution, (2) Table 2 shows the aircraft's RCS average value, and (3) Fig. 4 shows the RCS values of different regions of the strike fighter.

The simulation was conducted under conditions including: $\mathrm{X}$ band wave, $\mathrm{HH}$ polarization, monostatic radar, $0^{\circ}$ in elevation, and $0-360^{\circ}$ in azimuth. Fig. 3 shows the threesurfaces strike fighter's RCS distribution characteristics: (1) the average value of head-on RCS between $\pm 30^{\circ}$ is $\sigma_{d B s m}$ $=-4.163 \mathrm{dBsm}$, (2) the average value of broadside RCS between $\pm 30^{\circ}$ is $\sigma_{d B s m}=17.805 \mathrm{dBsm}$, and (3) the average value of tail-on RCS between $\pm 30^{\circ}$ is $\sigma_{d B s m}=13.118 \mathrm{dBsm}$.

To determine the average value characteristic, a simulation was conducted under conditions including $\mathrm{X}, \mathrm{S}$, $\mathrm{C}$, and L bands, $\mathrm{HH}$ polarization, monostatic radar, $-5^{\circ}, 0^{\circ}$, $5^{\circ}, 10^{\circ}$, and $15^{\circ}$ in elevation, and $0^{\circ} 360^{\circ}$ in azimuth. Twenty curves of RCS distribution were used to calculate the average value. Table 2 gives the RCS average values between $\pm 30^{\circ}$ from head-on, broadside, and tail-on of the aircraft.

Table 2 shows that:

(1) in the X band, the average value of head-on RCS between $\pm 30^{\circ}$ is about $-3.197 \mathrm{dBsm}$, and the broadside and tail-on values are about $17.805 \mathrm{dBsm}$ and $17.592 \mathrm{dBsm}$, respectively,

(2) in the S band, the average values of head-on, broadside, and tail-on RCS between $\pm 30^{\circ}$ are about -3.397 $\mathrm{dBsm}, 16.417 \mathrm{dBsm}$, and $12.224 \mathrm{dBsm}$, respectively,

(3) in the C band, the average values of head-on, broadside, and tail-on RCS between $\pm 30^{\circ}$ are about -4.326 dBsm, $16.444 \mathrm{dBsm}$, and $13.889 \mathrm{dBsm}$, respectively, and

(4) in the L band, the average values of head-on, broadside, and tail-on RCS between $\pm 30^{\circ}$ are about -5.919 dBsm, $14.005 \mathrm{dBsm}$ and 10.932dBsm, respectively.

In total, 7200 RCS distribution pictures resulted from the simulation of RCS distribution of the different regions. The

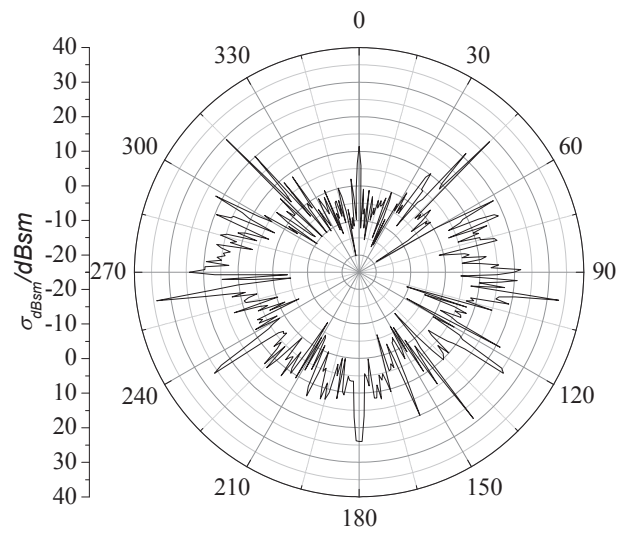

Fig. 3. Scattering characteristics of the three-surfaces strike fighter 
Table 2. RCS mean values of the three-surfaces strike fighter ( $\mathrm{dBsm}$ )

\begin{tabular}{|c|c|c|c|c|}
\hline \multirow{2}{*}{ Band } & \multirow{2}{*}{ Elevation angle } & \multicolumn{3}{|c|}{ RCS mean value of $\pm 30^{\circ}$} \\
\hline & & front view & side view & back view \\
\hline $\mathrm{X}$ & $+15^{\circ}$ & -5.857 & 12.465 & 15.511 \\
\hline X & $+10^{\circ}$ & -6.009 & 12.026 & 14.833 \\
\hline $\mathrm{X}$ & $+5^{\circ}$ & -3.197 & 12.712 & 17.592 \\
\hline X & $0^{\circ}$ & -4.163 & 17.805 & 13.118 \\
\hline $\mathrm{X}$ & $-5^{\circ}$ & -3.938 & 14.949 & 7.029 \\
\hline S & $+15^{\circ}$ & -4.818 & 16.217 & 12.224 \\
\hline S & $+10^{\circ}$ & -6.419 & 11.510 & 7.309 \\
\hline S & $+5^{\circ}$ & -3.397 & 12.712 & 17.592 \\
\hline S & $0^{\circ}$ & -7.424 & 12.557 & 6.108 \\
\hline S & $-5^{\circ}$ & -6.445 & 16.417 & 6.321 \\
\hline $\mathrm{C}$ & $+15^{\circ}$ & -5.136 & 15.068 & 13.811 \\
\hline $\mathrm{C}$ & $+10^{\circ}$ & -5.211 & 12.218 & 11.478 \\
\hline $\mathrm{C}$ & $+5^{\circ}$ & -4.571 & 12.172 & 13.889 \\
\hline $\mathrm{C}$ & $0^{\circ}$ & -4.326 & 16.444 & 8.726 \\
\hline $\mathrm{C}$ & $-5^{\circ}$ & -5.355 & 15.542 & 7.258 \\
\hline $\mathrm{L}$ & $+15^{\circ}$ & -5.919 & 10.931 & 10.932 \\
\hline $\mathrm{L}$ & $+10^{\circ}$ & -6.045 & 8.233 & 4.652 \\
\hline $\mathrm{L}$ & $+5^{\circ}$ & -6.278 & 10.300 & 4.256 \\
\hline L & $0^{\circ}$ & -8.708 & 11.945 & 3.304 \\
\hline L & $-5^{\circ}$ & -6.891 & 14.055 & 2.698 \\
\hline
\end{tabular}

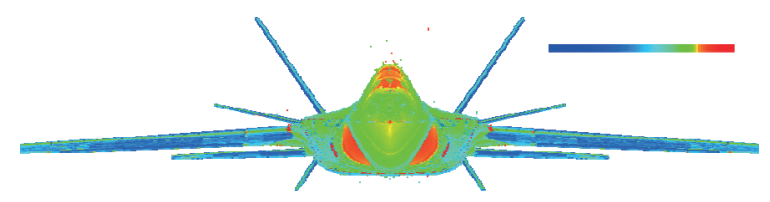

(a) Front view

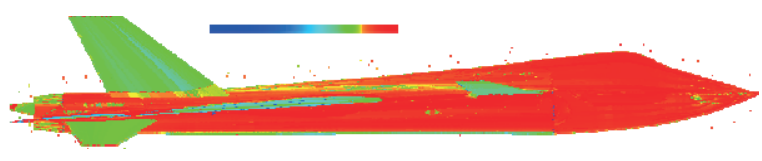

(b) Side view

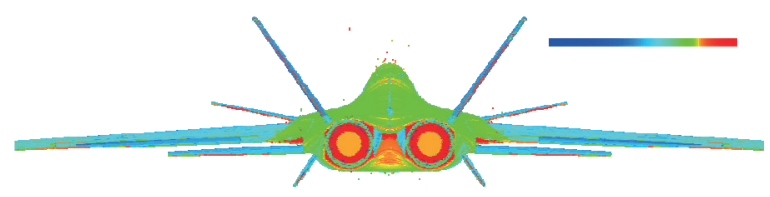

(c) Back view

Fig. 4. RCS distribution of the three-surfaces strike fighter simulations were conducted under conditions including: $\mathrm{X}$, $\mathrm{S}, \mathrm{C}$, and $\mathrm{L}$ bands, $-5^{\circ}, 0^{\circ}, 5^{\circ}, 10^{\circ}$ and $15^{\circ}$ in elevation, and $0^{\circ}$ $360^{\circ}$ in azimuth. Fig. 4 shows some typical results.

From Fig. 4, the RCS distribution characteristics of the three-surfaces strike fighter can be considered as: (a) the cockpit, convex closure of the inlet, and engine blades are the main scattering sources, viewed from the nose, (b) the aircraft nose, front fuselage, mid-fuselage, and rear fuselage have relatively strong scattering waves, from the side view, and (c) the nozzle and turbine blades are the main scattering sources viewed from the tail. Optimization measures should be applied to reduce the strong scattering wave of these major sources. The main stealth optimization measures in conceptual design include an edge-shaped front fuselage, a smooth transition between cockpit and fuselage, blended wing body configuration, V-tail and outward slanted pelvic fins, divert-less supersonic inlet (DSI) and S-shaped inlet, parallel edges of wings and tails, an embedded weapon bay, and saw tooth edges of hatch doors. All these measures can reduce the aircraft's RCS significantly.

The aircraft's nose-on RCS is affected mainly by the cockpit and inlet. Its side RCS is affected mainly by vertical tails, and the junction of the wing and fuselage. The rear RCS is affected mainly by the engine nozzle. External hanging missiles and fuel tanks will affect an aircraft's RCS at all azimuth angles. To reduce the aircraft's RCS, there are some typical measures: (1) Using a coated cockpit canopy to block incoming radar waves. (2) Using a DSI and S-shape inlet to hide the engine's blades and reduce the reflected radar wave in the inlet. The only issue with this inlet is that it will increase the fuselage drag and shorten the aircraft's range and endurance. (3) A wire mesh screen over the inlet can reduce the wave getting into the inlet but it will also reduce the air inflow and that will have a bad effect on engine performance. (4) An inward- or outwardcanted vertical tail will help to reduce aircraft's side RCS but it will also be an issue in fuselage weight control. (5) Wing-fuselage fusion can help to reduce the side RCS. (6) An internal weapon bay can help to reduce aircraft's RCS, see reference [8], but it needs a stronger fuselage structure and that means the fuselage will be heavier. An internal weapon bay will also increase the fuselage cross section and this will bring more drag force and worsen the aircraft's performance.

RCS average values at different bands, viewed from different angles, as well as the aircraft's RCS distribution, were simulated. These results help the subsequent RCS reduction and provide references for a stealth aircraft's conceptual design. 


\subsection{Aerodynamic computations}

A stealth aircraft's conceptual design needs both RCS simulation and aerodynamic computation. The digital prototyping of a strike fighter designed in conceptual design phase is used to finish the aerodynamic computation work. The Workbench software was used for computation. The grid number is about 19 million. The minimum cell distance of the grid cells is $6.628 \times 10^{-6} \mathrm{~m}$, which is acceptable. Fig. 5 shows the grids on the aircraft's surface.

The aircraft's flow field grids were imported into Fluent solver to analyze its aerodynamic characteristics.

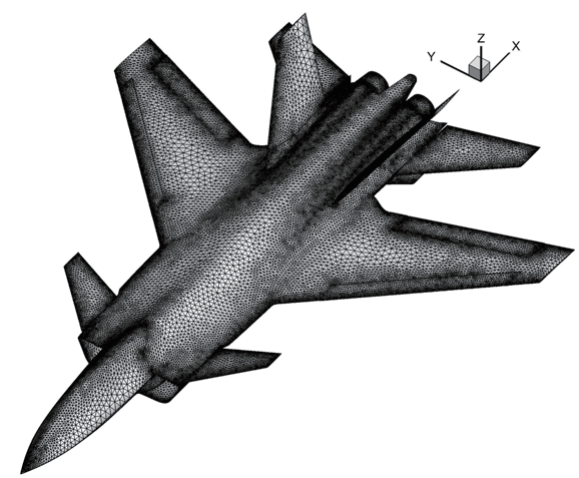

Fig. 5. Grids of the three-surfaces strike fighter

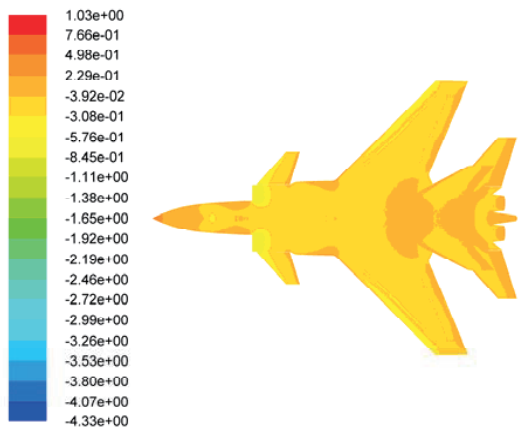

(a) Pressure coefficients on the upper surface
A density-based solver was used in view of the assumption that air is compressible when its velocity is above $0.3 \mathrm{Ma}$. A standard $k$ - $\varepsilon$ function was used as the turbulence model, as in formulae (6) and (7). A three-dimensional N-S function was used as fluent control function, as in formulae (8)(10). Referring to the Su-30SM fighter's high-altitude transonic performance, we focus on the three-surfaces attack fighter's high-altitude transonic performance. The air density at $8 \mathrm{~km}$ altitude is $0.525786 \mathrm{~kg} / \mathrm{m}^{3}$, and the far field pressure is $0.356516 \times 10^{5} \mathrm{~Pa}$, the viscosity coefficient is $1.5271 \times 10^{-5} \mathrm{~N} \cdot \mathrm{S} / \mathrm{m}^{2}$, the speed of sound is $308.11 \mathrm{~m} / \mathrm{s}$, the area of the wing is $72.26 \mathrm{~m}^{2}$, the free stream velocity is 0.8 $\mathrm{Ma}$, and the attack angle is $0^{\circ}$. Residual precision during the computation is set to be $10^{-5}$.

Figure 6 provides the results of a pressure coefficient distribution of the aircraft and its flow field. Fig. 7 gives the velocity distribution of the flow field; the pressure coefficient, drag coefficient, and lift-drag ratio can then be calculated.

As shown in Fig. 6, the pressure coefficients at the lips of DSI are higher, and they will be even higher at the corner of the $\mathrm{S}$ shape. This will cause a bigger drag force.

Figure 7 shows the external flow velocity distribution when the incoming stream is at a velocity of $0.8 \mathrm{Ma}$.

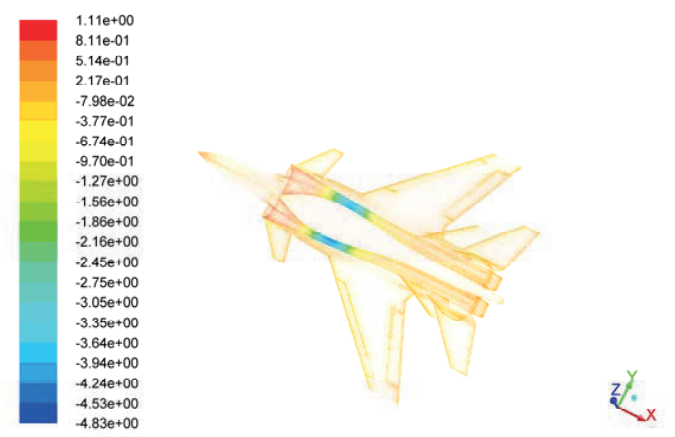

(c) Vector graph of pressure coefficients

Fig. 6. Pressure coefficient distribution of a three-surfaces attack fighter (unit: dimensionless) 
Supersonic flow will appear at the corner of the S shape but the flow speed will decrease to transonic before it arrives at the engine.

To date, the pressure and velocity distributions of the flow field are obtained by a CFD method. Characteristics of the aircraft's lift to drag ratio can also be obtained using the same method.

Table 3 gives the simulation results regarding the aircraft's lift to drag ratio. The simulation was conducted under conditions including pressure of the far field flow is

$35651.6 \mathrm{~Pa}$, velocity of the upstream is $0.8 \mathrm{Mach}$, and the aircraft's strike fight angle is between $-5^{\circ}$ and $+15^{\circ}$.

When flying at $8 \mathrm{~km}$ altitude and at an attack angle of $2.5^{\circ}$, with the speed of $0.8 \mathrm{Ma}$, the drag force and lift force of the aircraft are:

$$
\begin{aligned}
D & =\frac{1}{2} \rho v^{2} S C_{D}=0.5 \times 0.525786 \times(308.11 \times 0.8)^{2} \times 72.26 \times 0.04275 \\
& =49340 \mathrm{~N} . \\
L & =\frac{1}{2} \rho v^{2} S C_{L}=0.5 \times 0.525786 \times(308.11 \times 0.8)^{2} \times 72.26 \times 0.34674 \\
& =400196 \mathrm{~N} .
\end{aligned}
$$

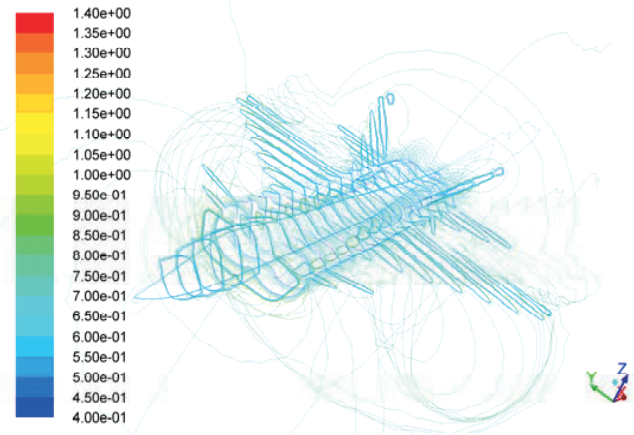

(a) Profile along the $x$ axis

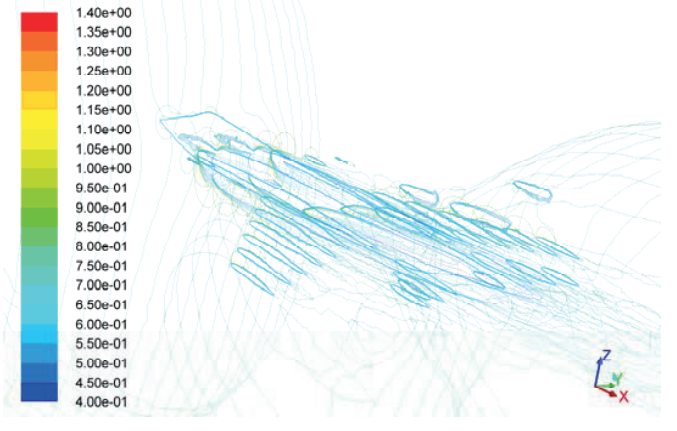

(b) Profile along the $y$ axis

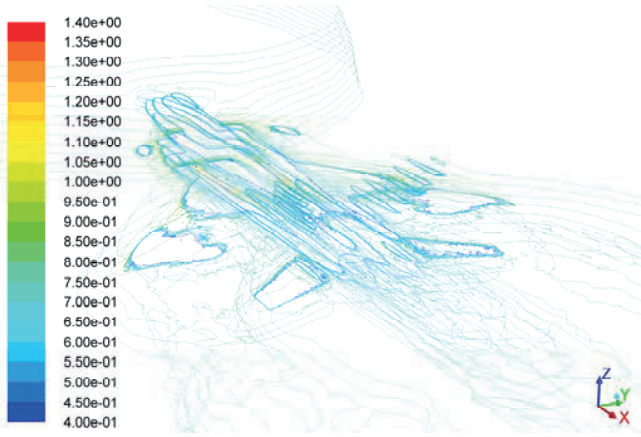

(c) Profile along the $z$ axis

Fig. 7. Velocity isoline of the three-surfaces attack fighter (unit: Mach)

Table 3. Lift and drag characteristics

\begin{tabular}{cccc}
\hline \multirow{2}{*}{ Attack angle $^{\circ}$} & \multicolumn{3}{c}{ Lift and drag characteristics } \\
\cline { 2 - 4 } & Lift coefficient & drag coefficient & Lift and drag ratio \\
\hline-5 & -0.15501 & 0.02846 & -5.44659 \\
0 & 0.19802 & 0.03013 & 6.57218 \\
2.5 & 0.34674 & 0.04275 & 8.11087 \\
5 & 0.55422 & 0.06720 & 8.24732 \\
10 & 0.89661 & 0.21319 & 4.20568 \\
15 & 1.12169 & 0.33335 & 3.36490 \\
\hline
\end{tabular}


When estimating its performance, roughly, L equals the aircraft's weight, and D equals the drag force. The normal thrust of AL-31F is 7620 daN and it will increase to 12258 daN when the after-burner is working. When equipped with two engines, the normal thrust will be $7620 \times 2 \times 10=152400$ $\mathrm{N}$ and the thrust with the after-burner is $12258 \times 2 \times 10 \mathrm{daN}$ $=245160 \mathrm{~N}$.

When the weight of the aircraft is $m=\frac{G}{\mathrm{~g}}=\frac{L}{\mathrm{~g}}=40836 \mathrm{~kg}=$ $40.836 \mathrm{t}$, at an altitude of $8 \mathrm{~km}$ and attack angle of $2.5^{\circ}$, the aircraft can keep a cruise speed of $0.8 \mathrm{Ma}$, the thrust needed is $49340 \mathrm{~N}$, smaller than the thrust that the engines can supply. So the aircraft can perform well and meet the basic design requirements.

Using the CFD method to estimate the pressure and velocity of the aircraft's flow field has been shown to be effective in accuracy and reliability. Thus, the method is suitable for the aerodynamic estimation of the aircraft in conceptual design.

\section{Conclusions}

This paper examined the conceptual design of a threesurfaces strike fighter and simulates its stealth and aerodynamic performance. The simulation results show that:

(1) The three-surfaces strike fighter's conceptual design meets the military aircraft's basic performance requirements of stealth and aerodynamics in air combat and ground attack. The aircraft has good performance in stealth as well as transonic aerodynamic characteristics at very low altitudes.

(2) The three-surfaces strike fighter performs well from the perspective of low detectability; its average value of head-on RCS between $\pm 30^{\circ}$ is below $-3.197 \mathrm{dBsm}$; its average value of broadside RCS between $\pm 30^{\circ}$ is below $1.805 \mathrm{dBsm}$, and its average value of tail-on RCS between $\pm 30^{\circ}$ is below $17.592 \mathrm{dBsm}$.

(3) The pressure and velocity distribution of the flow field meets basic aerodynamic requirements; the lift coefficient is 0.34674 , the drag coefficient is 0.04275 , and the lift-todrag ratio is 8.11087 when the aircraft's attack angle is $2.5^{\circ}$.

This paper focuses on the conceptual design of a threesurfaces stealth strike fighter and simulates its stealth and aerodynamic performance. These results may help in the aircraft's general and stealth designs.

\section{References}

[1] Anonymous, "Obama Pledges F-22 Veto As Senate
Gears Up For Aircraft Fights," Journal of Defense Daily, Vol.243, No. 9, 2009, pp. 57-62.

[2] Starosta, G., "The F-35 readies for takeoff," Journal of Air Force Magazine, Vol. 96, No.4, 2013, pp. 38-42.

[3] Wise, K.A., Lavretsky, E., "Robust and adaptive control of X-45A J-UCAS: A design trade study," Journal of IFAC Proceedings Volumes (IFAC-PapersOnline), Proceedings of the 18th IFAC World Congress, Vol,18, No.1, 2011, pp. 6555-6560.

[4] Hang, Z., Huijun, T., Xiangping, L., "Flow structure and performance characteristics of X-47-like slot-shaped inlet," Journal of Acta Aeronautica et Astronautica Sinica, Vol.30, No.12, 2009, pp. 2243-2249.

[5] Binxin, G., Wenkang, W., "Investigation on flow control of triplane in the water tunnel," Journal of Experiments in Fluid Mechanics, Vol. 21, No.1, 2007, pp. 50-53.

[6] Zhipeng, X., Zhiqiang, W., "Maneuver Load Optimal Distribution Between Canard and Horizontal Tail of Threesurface Aircraft," Journal of Acta Aeronautica et Astronautica Sinica, Vol. 30, No. 2, 2009, pp. 276-282.

[7] Xing, L., Zhenghong, G., Yan, L., "Longitudinal optimal trim ming points research for three-surface CRW aircraft," Journal of Flight Dynamics, Vol. 28, No.3, 2010, pp. 13-16.

[8] Kuizhi, Y., Cong, S., Jinzu, J., "Numerical Simulation on the Stealth Characteristics of twin-vertical-tails for fighter," Journal of Beijing University of Aeronautics and Astronautics, Vol. 40, No. 2, 2014, pp. 160-165.

[9] Kuizhi, Y., Cong, S., Hu, L., "Numercal simulation on the RCS of combat aircraft for mounted missile," Journal of Systems Engineering and Electronics, Vol. 36, No. 1, 2014, pp. 62-67.

[10] Jianhua, S., "Low-Observable technologies of Aircraft[M]," Aviation Industry Press, BeiJing, 2013, pp.1-5.

[11] FumiyaTogashi, TakeshiFujita, YasushiIto, "CFD computa- tions of NAL experimental airplane with rocket booster using overset unstructured grids," Int. J. Numer. Meth. Fluids, Vol. 48, No. 8, 2005, pp. 801-818.

[12] Forrester T. Johnson, Edward N. Tinoco, N., Jong Y., "Thirty years of development and application of CFD at Boeing Commercial Airplanes," Journal of Computers and Fluids, Vol. 34, No. 10, 2005, pp. 1115-1151.

[13] Kazuhiro Nakahashi, "Aeronautical CFD in the age of Petaflops-scale computing: From unstructured to Cartesian meshes," Journal of European Journal of Mechanics / B Fluids, Vol. 40, 2013, pp. 75-86.

[14] D. Vallespin, K.J.Badcock, A.Da Ronch, "Computational fluid dynamics framework for aerodynamic model assessment," Journal of Progress in Aerospace Sciences, Vol. 52, 2012, pp. 2-18.

[15] S. Saha, B. Majumdar, "Flow Visualization and CFD Simulation on $65^{\circ}$ Delta Wing at Subsonic Condition," Journal of Procedia Engineering, Vol. 38, 2012, pp. 3086-3096. 